\section{Commentary: MANTAstic!}

\author{
Jay K. Bhama, MD
}

In this issue of the Journal, Shah and colleagues ${ }^{1}$ from University of Maryland report on their retrospective observational experience with decannulation of extracorporeal membrane oxygenation (ECMO) support using the MANTA large-bore vascular closure device. The study details their experience with 10 consecutive patients who underwent decannulation using the device. All patients achieved successful closure with immediate hemostasis and without stenosis at the closure site. Three patients experienced perioperative complications, including 1 hematoma, 2 pseudoaneurysms, and 1 acute lower limb ischemia. The authors describe the main advantage of this technique as the avoidance of a groin incision and its numerous attendant complications, including infection and lymphocele.

As the authors aptly point out in their discussion, alternative options to open surgical decannulation are largely limited to pulling the cannulas and holding direct manual pressure. Although many centers, including ours, adopt this technique, the authors are astute to point out that this approach is fraught with not only potential late complications, such as hematoma and pseudoaneurysm formation, but also early complications, such as lack of immediate hemostasis. Although the latter has not been a problem in our experience, the former remains largely unevaluated except for an anecdotal impression that these complications are not very common.

So how does the MANTA device help us in the ECMO population? Will it really transcend open surgical

From the Department of Cardiothoracic Surgery and Baptist Heart Failure and Transplant Institute, Baptist Health Medical Center and Division of Cardiovascular Surgery, University of Arkansas for Medical Sciences, Little Rock, Ark.

Disclosures: The author reported no conflicts of interest.

The Journal policy requires editors and reviewers to disclose conflicts of interest and to decline handling or reviewing manuscripts for which they may have a conflict of interest. The editors and reviewers of this article have no conflicts of interest.

Received for publication Dec 13, 2020; revisions received Dec 13, 2020; accepted for publication Dec 21, 2020; available ahead of print Dec 25, 2020.

Address for reprints: Jay K. Bhama, MD, Department of Cardiothoracic Surgery \& Heart Failure and Transplant Institute, Baptist Health Medical Center, 9601 Baptist Health Dr, Suite 990, Little Rock, AR 72205 (E-mail: bhamajk@me.com).

JTCVS Techniques 2021;6:84

2666-2507

Copyright $(2020$ The Authors. Published by Elsevier Inc. on behalf of The American Association for Thoracic Surgery. This is an open access article under the CC BY-NCND license (http://creativecommons.org/licenses/by-nc-nd/4.0/).

https://doi.org/10.1016/j.xjtc.2020.12.015

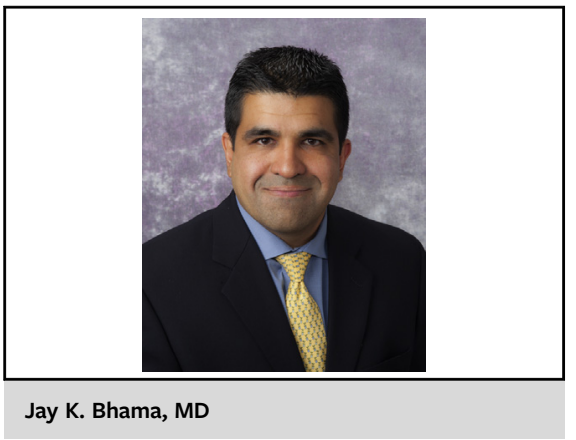

CENTRAL MESSAGE

The MANTA device offers a novel and effective approach to ECMO decannulation.

decannulation or simply holding pressure? Answers to some of these questions will depend on the ease of use of the device, its adaptability for use by non-surgeons who are more commonly involved in ECMO deployment, and of course its cost. Certain parallels obviously can be drawn from the transcatheter aortic valve replacement experience, where percutaneous closure devices are used nearly uniformly and are largely considered the standard of care. Despite the far more elective nature of transcatheter aortic valve replacement compared with ECMO, it is not surprising that there is a thirst for a better answer to ECMO decannulation than the currently available and invasive surgical approach or the rather nebulous "hold pressure and pray" approach.

The limitations of the study are clear, in that the small numbers of patients preclude definitive conclusions and, as the authors suggest, further investigation in larger cohorts is certainly warranted. Nonetheless, the $100 \%$ technical success rate is rather impressive and bodes well for a "MANTAstic" future for this device!

\section{Reference}

1. Shah A, Ghoreishi M, Taylor BS, Toursavadkohi S, Kaczorowski DJ, the University of Maryland Medical Center Extracorporeal Membrane Oxygenation (UMMC ECMO) Group. Complete percutaneous decannulation from femoral venoarterial extracorporeal membrane oxygenation. J Thorac Cardiovasc Surg Tech. $2021 ; 6: 75-81$. 